\title{
Urethral squamous cell carcinoma presenting as a Fourniere's Gangrene
}

\author{
Adam Christie $^{1}$, Nathan Lawrentschuk ${ }^{2}$, Ajay Chauhan ${ }^{3}$ and Satish Warrier ${ }^{1}$ \\ ${ }^{1}$ Colorectal Surgery Department, Peter MacCallum Cancer Centre, Australia \\ ${ }^{2}$ Urology Department, Peter MacCallum Cancer Centre, Australia \\ ${ }^{3}$ Plastic Surgery Department, Peter MacCallum Cancer Centre, Australia
}

\section{Case report}

Urothelial carcinoma is a rare but aggressive Urological malignancy that accounts for less than $1 \%$ of urological malignancies [1]. The age standardised ratio is estimated as 1.1/1,000,000 [2]. It is often difficult to diagnose given its non-specific symptoms which include pain, dysuria, obstructive voiding, or urethral strictures [3]. We review a case of Urethral Squamous cell carcinoma (SCC) presenting as Fourniere's Gangrene and highlight the challenges in management of the condition.

A 47 year old man presented with a 2 month history of scrotal pain. A gangrenous urethra and a perineal abscess with frank pus draining from a sinus were noted on physical examination. Multiple debridements of the left hemiscrotum and perineum were performed at an outside hospital, without resolution of the Fourniers, depite 3 hospital admissions. Eventually, histopathology following a urethrectomy demonstrated a Urethral SCC. Magnetic resonance imaging (MRI) confirmed a lesion involving the Corpora Spongiosum with Spermatic cord involvement and Positron emission tomography showed an FDGavid lesion in the groove between the anterior abdominal wall and the penile bulb. It was noted on Examination under anaesthesia of the rectum that the lower border of the tumour abutted and invaded the sphincter complex. Prominent Inguinal Lymph nodes were biopsied but demonstrated no evidence of SCC.

In the absence of distal metastases, the multidisciplinary consensus was for a Total Pelvic Exenteration with curative intent.

Intraoperative findings demonstrated a fungating growth at the penoscrotal junction arising from the penile urethra. There was involvement of the scrotal skin, right testicle, spermatic cord and

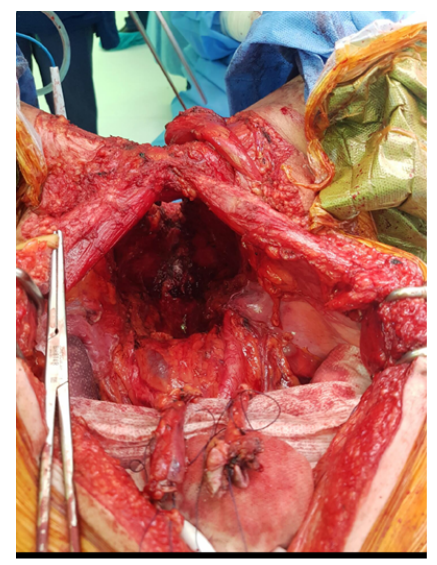

Figure 1. Intraoperative Cranial view following complete surgical resection. perineum and the tumour extended above the anal sphincter. High anterior resection was performed with en bloc cystoprostatectomy, penectomy and scrotectomy with ileal conduit and end colostomy creation (Figures 1 and 2). A right sided myocutaneous anterolateral thigh flap and a left myocutaneous vertical rectus abdominus flap were used to reconstruct the groin and perineal defects (Figure 3).

The Final histopathology demonstrated a $70 \mathrm{~mm}$ well differentiated squamous cell carcinoma of the spongy part of the urethra, invading corpus spongiosum and adipose stroma with a maximum radial invasive thickness of $20 \mathrm{~mm}$, well clear of surgical margins. The patient had a relatively uneventful recovery and on 3monthly review the abdominal wound and the myocutaneous flaps had healed well.

\section{Discussion}

Current evidence remains inconclusive in regards to long term survival following treatment, however, Urethral SCC is generally associated with a poor 5 year survival rate of $5-15 \%$ [4]. Treatment

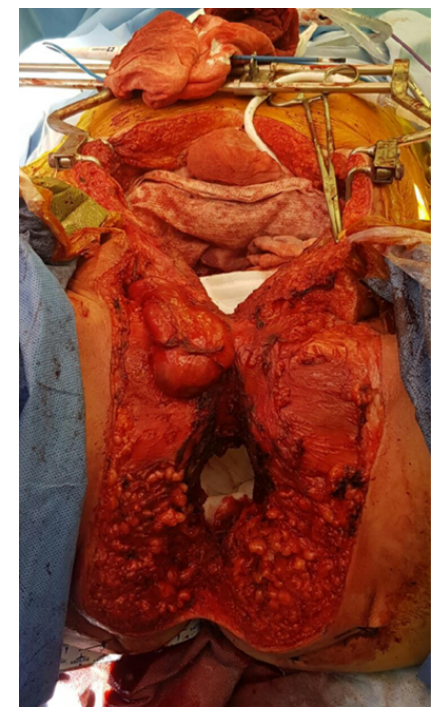

Figure 2. Intraoperative Caudal view following complete surgical resection.

Correspondence to: Satish Warrier, Level 7 Peter MacCallum Cancer Centre. 305 Grattan Street, Melbourne Victoria 3000, Tel: 0488054238; E-mail: satishwarrier96101@gmail.com

Received: March 02, 2017; Accepted: March 17, 2017; Published: March 21 , 2017 


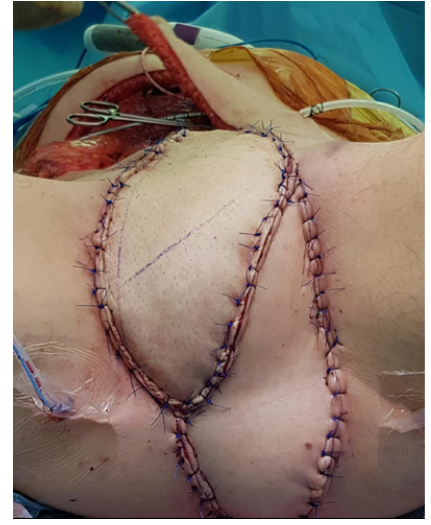

Figure 3. Intraoperative view of the perineal defect post right sided myocutaneous anterolateral thigh flap and left myocutaneous vertical rectus abdominus flap.

of these malignancies remain controversial given the limited number of cases. Radical surgical resection however, remains the mainstay of treatment for locally invasive tumours in the absence of metastatic disease [5]. Current guidelines suggest partial or total penectomy is required if there is established invasion into the corpora cavernosum. Primary chemoradiotherapy can be considered in the event of a T1-2 N0 tumour [6].

To our knowledge only four other cases have been reported where a urethral abscess was subsequently diagnosed as a Urothelial carcinoma [7-10]. In 3 out of the previous 4 documented cases the patient was treated with multiple debridements and the administration of broad spectrum antibiotics without resolution, and there was a delayed time to histopathological diagnosis as in our case. Delayed diagnosis is a well-known phenomenon with urothelial carcinoma and likely has an influence on prognosis [4].

Our case highlights the need to consider urothelial carcinoma in the case of recurrent Urethral or Scrotal Abscess not amenable to surgical debridement and antibiotic administration. There is limited data on the outcomes of this malignancy following radical resection and multiinstitution involvement is required to clarify the appropriateness of this approach.

\section{Acknowledgements}

The author(s) would like to acknowledge the staff at Peter MacCallum Cancer Centre involved in the care of this patient.

\section{Disclosures of interest}

The author(s) declare no potential conflicts of interest.

\section{References}

1. Gakis G, Witjes JA, Compérat E, Cowan NC, De Santis M, et al. (2013) EAU guidelines on primary urethral carcinoma. Eur Urol 64: 823-830.[Crossref]

2. Visser O, Adolfsson J, Rossi S, Verne J, Gatta G, et al. (2012) Incidence and survival of rare urogenital cancers in Europe. Eur J Cancer 48: 456-464.[Crossref]

3. Ayyildiz A, Karaguzel E, Huri E, Turgut AT, Nuhoglu B, et al. (2006) Squamous cell carcinoma of the male bulbomembranous (proximal) urethra--how should the treatment be done? A case report and review of the literature. Int Urol Nephrol 38: 495-499. [Crossref]

4. Karnes RJ, Breau RH, Lightner DJ (2010) Surgery for urethral cancer. Urol Clin North Am 37: 445-457.[Crossref]

5. Dalbagni G, Zhang ZF, Lacombe L, Herr HW (1999) Male urethral carcinoma: analysis of treatment outcome. Urology 53: 1126-1132.[Crossref]

6. (2017) NCCN guidelines Version 1. Updates Penile Cancer.

7. Medina Pérez M, Valero Puerta J, Sánchez González M, ValpuestaFernández I, Marín Martín J (1999) [Squamous carcinoma of the male urethra, its presentation as a scrotal abscess]. Arch Esp Urol 52: 792-794.[Crossref]

8. Dickinson AJ, Hastie KJ, Charlton CA (1990) Primary squamous carcinoma of the male urethra presenting as a periurethral abscess. Br J Urol 65: 217.[Crossref]

9. Angulo JC, Larrinaga JR, Unda-Urzaiz M, Ereño C, Flores N (1992) Squamous cell carcinoma of the male urethra mimicking a paravertebral abscess. UrolInt 48: 108-110. [Crossref]

10. Moore S, Rashidipour O, Moore RB (2016) Primary Metastatic Squamous Cell carcinoma of the male Urethra Presenting with Scrotal Abscess and Subsequent Development of Fournier's Gangrene. Clin Med Insights Case Rep 9: 83-86. [Crossref]

Copyright: $\odot 2017$ Christie A. This is an open-access article distributed under the terms of the Creative Commons Attribution License, which permits unrestricted use, distribution, and reproduction in any medium, provided the original author and source are credited. 